\title{
Durability under thermal loads of polyvinyl alcohol fibers
}

\author{
Margareth Silva Magalhães ${ }^{1}$, Romildo Dias Toledo Filho ${ }^{2}$, \\ Eduardo Moraes Rego Fairbairn ${ }^{2}$
}

\footnotetext{
${ }^{1}$ Department of Civil Construction and Transportation, Universidade do Estado do Rio de Janeiro - UERJ: Rua São Francisco Xavier 524 - room 5005A, Maracanã, CEP: 20550-900 Rio de Janeiro - RJ Brazil.

e-mail: margarethsm@yahoo.com.br

${ }^{2}$ Department of Civil Engineering, COPPE/ Universidade Federal do Rio de Janeiro, P.O. Box 68506, CEP 21941-972,

Rio de Janeiro - RJ, Brazil.

e-mail: toledo@coc.ufrj.br; eduardo@coc.ufrj.br
}

\begin{abstract}
In the present paper, the thermal durability of polyvinyl alcohol fibers (PVA) was studied after fiber samples had been subjected to temperatures ranging from $90^{\circ} \mathrm{C}$ to $250^{\circ} \mathrm{C}$. Residual mechanical properties, such as tensile strength, elastic modulus and elongation at break, and physical properties, such as density were determined. Weibull statistics were used to quantify the degree of variability in fiber strength, at the different temperature. In addition, thermal analysis of PVA fibers were carried out employing thermogravimetry and differential scanning calorimetry up to the temperature of $800^{\circ} \mathrm{C}$. SEM analysis of heated and unheated samples had been carried out in order to allow the identification of the changes in the microstructure of the fibers. The degradation process of PVA fibers manifests itself in a significant loss of mass, stiffness and strength of the fibers, which is progressive with increasing temperature. Thermal analysis has shown that the melting point of PVA fibers begins at approximately $200^{\circ} \mathrm{C}$ and thermal degradation initiates at about $239^{\circ} \mathrm{C}$. However, progressive loss in tensile strength and elastic modulus was observed starting at a temperature as low as $90^{\circ} \mathrm{C}$, due to glass transition temperature of PVA fibers at approximately $66^{\circ} \mathrm{C}$. At $220^{\circ} \mathrm{C}$, the elastic modulus and strength were reduced at about $45 \%$ and $52 \%$, respectively, when compared with respective values of unheated samples. With regards to Weibull modulus, the statistical parameter did not exhibit significant influence on temperature for samples heated up to $145^{\circ} \mathrm{C}$, which ranged from 23.4 to 28.8 . However, samples heated to $220^{\circ} \mathrm{C}$ showed a sudden reduction in Weibull modulus to 8.6, indicating that a significant change occurred in the populations of fracture inducing flaws at this temperature level, which clearly affect the tensile strength and Weibull modulus.
\end{abstract}

Keywords: PVA fiber, thermal durability, thermal analysis, residual properties, Weibull modulus.

\section{INTRODUCTION}

Polyvinyl alcohol fibers (PVA) are synthetic fibers obtained from polyviny 1 acetate which is readily hydrolysed by treating an alcoholic solution with aqueous acid or alkali [1]. The fibers possess an ideal combination of properties and find applications on a large scale around the world in industry and agriculture. Items such as fishing and seaweed nets, ropes, hoses, belts, tire codes and paper making felts are made from those fibers, which serve as well as reinforcing material for cementitious composites [2, $\underline{3}]$.

PVA fibers used for reinforcing material have the following advantages: high strength $(800-1500 \mathrm{MPa})$, elongation capacity of about $6 \%$ and high modulus of elasticity (23 - 41GPa) and furthermore do not present any health risk during usage $[\underline{4}, \underline{5}]$.

There are several types of PVA fibers, each fitting a separate application. The fibers used in this research are of type REC15, manufactured by Kuraray, Japan. REC15, one of the new types of PVA fiber, has been designed for strain hardening cementitious composites (SHCC) with the purpose to control the fiber-matrix bond, due to the hydrophilic nature of PVA fibers $[\underline{6}, \underline{4}, \underline{7}]$.

SHCC is a special type of high performance fiber reinforced cementitious composite, which exhibits a strain hardening behaviour under tension loads with multiple cracking and features a strain-stress curve with a shape similar to that of a ductile metal with yielding point []. The high ductility (strain capacity typically 
exceeds 3\%) associated with strain hardening behaviour has resulted in more durable structures [ $[\underline{6}, \underline{9}]$.

In order to obtain a better understanding of the thermal behaviour of SHCC, it is of great interest to study the behaviour of reinforcement fibers subjected to thermal conditions considering that, the mechanical properties of composites are highly depending on the properties of reinforcement fibers.

This study focused on the influence of high temperature exposure on PVA fibers behaviour. The fibers were investigated after being subjected to temperatures up to $250^{\circ} \mathrm{C}$ in terms of residual mechanical properties, such as tensile strength, elastic modulus and elongation at failure, and physical properties, such as density. To study the deterioration mechanism of PVA fibers under thermal loads, thermal analysis (TG/DTG/DSC) and microscopic analysis of heated and unheated samples had been carried out. Weibull statistics were used to quantify the degree of variability in yarn strength at different temperature levels.

\section{EXPERIMENTAL PROGRAM}

\subsection{Material}

Polyvinyl alcohol (PVA) fibers with trade-name REC15 and manufactured by Kuraray Co - Japan, with a diameter of $40 \mu \mathrm{m}$, density of $1.3 \mathrm{~g} / \mathrm{cm}^{3}$, modulus of $40 \mathrm{GPa}$ and tension strength of $1600 \mathrm{MPa}$ (data provided by the manufacturer), was used in this experiment.

The surface of the PVA fibers is coated with a proprietary hydrophobic oiling agent of $1.2 \%$ by weight to control the interfacial bonding properties between the fiber and matrix for composite performance [6].

\subsection{Heating of samples}

PVA fiber samples were heated in an electric furnace from room temperature $\left(\sim 20^{\circ} \mathrm{C}\right)$ to peak temperatures of $90^{\circ} \mathrm{C}, 110^{\circ} \mathrm{C}, 145^{\circ} \mathrm{C}, 190^{\circ} \mathrm{C}, 220^{\circ} \mathrm{C}$ and $250^{\circ} \mathrm{C}$ at a slow increasing rate of $1^{\circ} \mathrm{C} / \mathrm{min}$. When the target peak temperature was reached, the furnace temperature was maintained for 60 minutes and then the furnace was turned off and samples were allowed to cool down to room temperature. Tests were performed when the samples were cool enough to handle.

\section{TEST PROCEDURE}

\subsection{Thermal analysis of PVA fiber}

Thermogravimetry (TG) and differential scanning calorimetry (DSC) were performed in simultaneous analyses equipment TG/DTA/DSC TA - Instruments, model SDT Q600, with a $10^{\circ} \mathrm{C} / \mathrm{min}$ constant heating rate, from 35 to $800^{\circ} \mathrm{C}$ in nitrogen flow $(100 \mathrm{~mL} / \mathrm{min})$. Samples of about $4 \mathrm{mg}$ were used in open platinum pans.

\subsection{Residual density tests}

Helium pycnometer model AccuPyc 1340 acquired from Micrometrics Instrument Corporation (USA) was used to measure the absolute density of unheated and after heating fiber samples. The samples, of about $3 \mathrm{~g}$ each, were previously dried at $40 \pm 1^{\circ} \mathrm{C}$ up to constant mass and then placed in desiccators. They remained in the desiccators until they were individually removed, had their weight recorded and transferred to the pycnometer chamber.

The helium gas was then admitted into the cell chamber filling the pores. This procedure was repeated according to the number of the pre-determined runs (five were used in this work). At the end of the last run a summary report was printed out giving the density for each run, the average sample absolute density and their standard deviations.

\subsection{Tensile tests}

Tensile tests were performed on heated and unheated samples following the procedures established by the ASTM D3822-2007 [10]. Thirty single yarn samples with the gage length of $30 \mathrm{~mm}$ were tested under tension load.

For this test cardboard rectangles of $60 \times 70 \mathrm{~mm}$ were prepared. An opening of $20 \times 30 \mathrm{~mm}$ was cut into the cardboard centre to which randomly selected samples, glued to slotted paper holders, were inserted (Figure 1b). The sample with the paper holder was mounted into a tensile test rig. Tests were started after the outer edges of the cardboards were carefully cut. Samples were stretched until failure at a rate of $0.5 \mathrm{~mm} / \mathrm{min}$. A 
1000N load cell was used to measure load. The tensile test rig and the sample set up are shown in Figure 1a. Before the tensile test, the cross sectional area was evaluated from the diameter measured by the scanning electron microscope for each sample. Loads and corresponding displacements were continuously recorded during the tests.

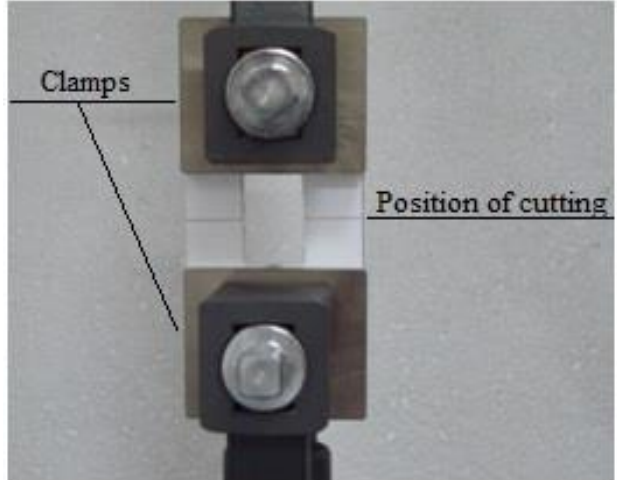

(a)

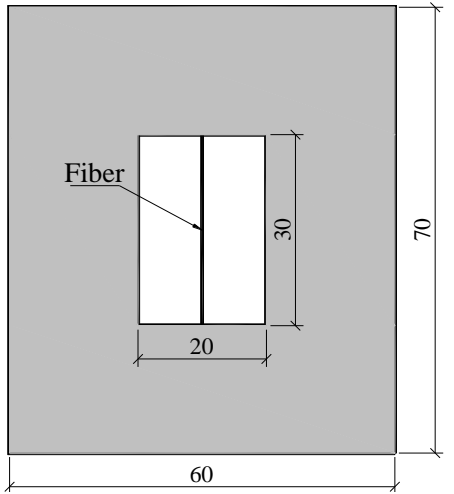

(b)

Figure 1: Tensile test setup (a) and specimen setup (b) (all dimensions in millimeter).

To accurately measure of Young's modulus and elongation of fiber, the compliance of the loading and gripping system was determined by obtaining the force versus displacement behaviour of the fiber at various gage lengths following the methodology used by SILVA et al [11] and CHAWLA et al [12]. The total crosshead displacement during fiber testing, $\delta$ t, is expressed by:

$$
\frac{\delta_{\mathrm{t}}}{\mathrm{F}}=\left(\frac{1}{\mathrm{EA}}\right) 1+\mathrm{c}
$$

Where $\mathrm{c}$ is the machine compliance, $\mathrm{F}$ is the applied force, $\mathrm{E}$ is the Young's modulus of the fiber, and $\mathrm{A}$ is the cross-sectional area of the fiber. Thus, a plot of $\delta \mathrm{t} / \mathrm{F}$ versus 1 (gage length), will yield a straight line of slope $1 /(\mathrm{EA})$ and intercept $\mathrm{c}$, the compliance of the load train. As a result, the machine compliance (c) of 0.028 was obtained.

Weibull statistics were used to quantify the degree of variability in fiber failure strength at different temperature levels. According to the Weibull analysis $[\underline{13}, \underline{14}]$, the failure probability under a uniform stress state is given by:

$$
P(\sigma)=1-\exp \left[-\left(\frac{\sigma}{\sigma_{0}}\right)^{\mathrm{m}}\right]
$$

Where $\sigma$ is the fiber strength for a given probability of survival, $\sigma o$ is defined as the characteristic strength and $\mathrm{m}$ is the shape parameter (often referred as Weibull modulus). The higher the value of $\mathrm{m}$ the lower the variability in strength.

Probabilities of failure were determined using ranking statistics [13]. Ordering the failure data from smallest to largest and assigning a ranking number $i$, the probabilities of failure were then assigned by the following relationship:

$$
\mathrm{P}(\sigma)_{\mathrm{i}}=\frac{\mathrm{i}}{\mathrm{N}+1}
$$

Where $\mathrm{P}(\sigma) \mathrm{i}$ is the probability of survival corresponding to its strength value and $\mathrm{N}$ is the total number of fibers tested. Substituting Eq. (3) into Eq. (2) yields:

$$
\ln \left[\ln \left[\frac{\mathrm{N}+1}{\mathrm{~N}+1-\mathrm{i}}\right]\right]=\mathrm{m} \cdot \ln \sigma-\mathrm{m} \cdot \ln \sigma_{\mathrm{o}}
$$


The Weibull parameter $(\mathrm{m})$ is obtained by linear regression by plotting $\ln \left[\ln \left[\frac{\mathrm{N}+1}{\mathrm{~N}+1-\mathrm{i}}\right]\right]$ against $\ln \sigma$.

\section{EXPERIMENTAL RESULTS AND DISCUSSIONS}

\subsection{Thermal analysis of PVA fiber}

TG and DTG curves of PVA fibers are shown in Figure 2. The TG results indicate that the onset degradation temperature of the PVA fiber is about $239^{\circ} \mathrm{C}$. Three temperature regions of mass loss can be identified in the TG/DTG curves. In the first region $\left(239^{\circ} \mathrm{C}-300^{\circ} \mathrm{C}\right)$ the fiber samples experienced a mass loss of about $4 \%$ due to partial dehydration of PVA accompanied by polyene formation [ $\underline{15}, \underline{16}]$. In the second region (between $300^{\circ} \mathrm{C}-410^{\circ} \mathrm{C}$ ), with a maximum decomposition rate at $371^{\circ} \mathrm{C}$, the PVA fiber suffered a more intense mass loss of $71 \%$ due to polyene decomposition yielding low-mass oxygen containing products (such as, acetaldehyde, benzaldehyde, acrolein) and the decomposition of polyene macroradicals to cis and trans derivatives [15, 17]; while in the third region (between $410^{\circ} \mathrm{C}-480^{\circ} \mathrm{C}$ ), the mass loss was $20 \%$ due to thermal decomposition of primary polyenes to cis and trans derivatives followed by their cyclization and the condensation of polyaromatic structures [17]. The residual percentage of the weight was equal to $1.5 \%$ at approximately $800^{\circ} \mathrm{C}$.

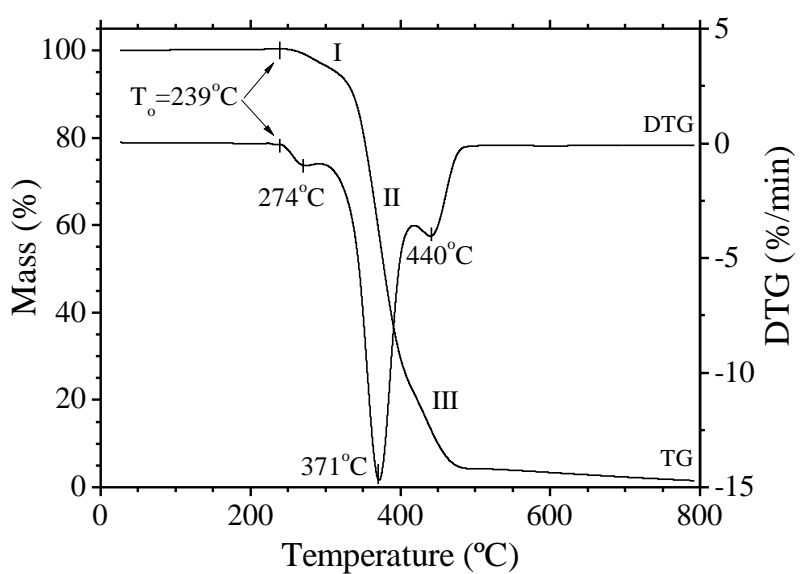

Figure 2: Thermogravimetry (TG) and differential thermogravimetry (DTG) curves

A differential scanning calorimetry (DSC) was applied for determining information of glass transition (Tg) and melting $(\mathrm{Tm})$ temperatures. Figure 3 a shows the DSC curve of PVA sample in the range of temperature from $20^{\circ} \mathrm{C}$ up to approximately $800^{\circ} \mathrm{C}$. The plot shows the heat flow as a function of sample temperature and an endothermic response is oriented downwards. The onset melting temperature (To) was determined at the temperature at which a deflection from the established baseline is first observed. The value of $\mathrm{Tg}$ was determined by the point on the thermal curve corresponding to $1 / 2$ the heat flow difference between the extrapolated onset temperature (Tf) and temperature of return to baseline (Tr) in the DSC curve (Figure 3b), according to recommendation of ASTM E1356 [18].

The DSC curve shows a glass transition (Tg) of approximately $66^{\circ} \mathrm{C}$. This value of $\mathrm{Tg}$ is in agreement with that reported previously in the literature $[\underline{19}, \underline{20}]$. Melting peak is observed at $244^{\circ} \mathrm{C}$ with an onset melting temperature (To) at $200^{\circ} \mathrm{C}$. Additional endothermic and exothermic peaks are observed at $354^{\circ} \mathrm{C}$ and $493^{\circ} \mathrm{C}$, and these are thought to be due to the degradation process of the fibers constituents. 


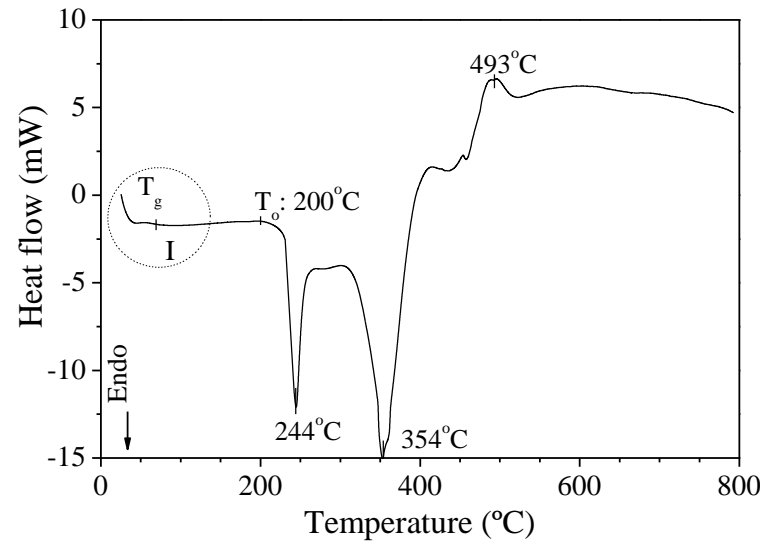

(a)

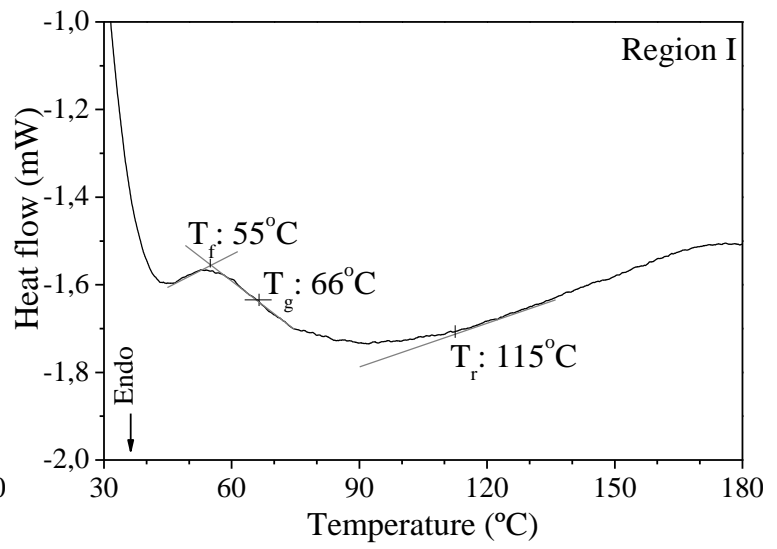

(b)

Figure 3: (a) Differential scanning calorimetry (DSC) curve and (b) DSC of the region I selected in (a)

\subsection{Tensile properties of PVA fibers after exposure to elevated temperatures}

The stress-strain behaviour of the PVA fiber, showing the "as-measured" data and that corrected for load strain compliance, is presented in Figure 4. Strain was calculated from cross-head displacement of the machine taking into account the machine compliance. Thus, the tensile strain $(\varepsilon)$ of samples was determined by the following equation: $\varepsilon=(\Delta \mathrm{L}-\mathrm{cF}) / \mathrm{l}$, where $\Delta \mathrm{L}$ is the cross-head displacement, $\mathrm{c}$ the machine compliance, $\mathrm{F}$ the applied force and 1 the gage length. The initial elastic modulus was determined on the basis of corrected stress - strain curves as the tangent of the inclination angle of the straight line connecting the origin with the point corresponds to $0.4 \%$ of strain.

All samples tested (unheated and heated samples) failed in a brittle manner by exhibiting a sharp drop in strength after failure stress. The tensile strength and elastic modulus for unheated PVA were 1576.2 MPa and 39.9 GPa respectively. This finding is consistent with the work of other researchers [4, $\underline{21}, \underline{22}]$.

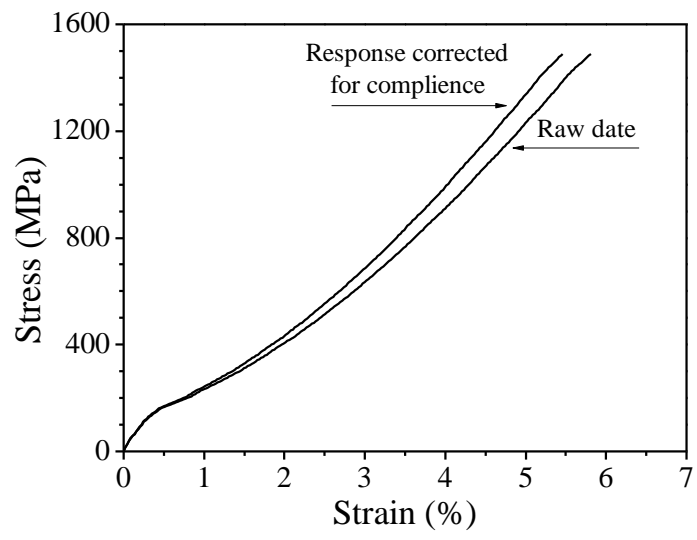

Figure 4: Stress-strain behaviour of a PVA fiber sample, showing the "as-measured" data and that corrected for load strain compliance.

Figure 5, Figure 6 and Figure 7 show the elastic modulus, tensile strength and elongation at break as a function of exposure temperature. The results presented show that, with an increase in temperature, the fiber degradation process identified in the TG/DTG and DSC tests resulted in reduction of fiber strength and initial elastic modulus. For example, after initial heating up to $90^{\circ} \mathrm{C}$, both the elastic modulus and tensile strength of the PVA are reduced by approximately $4 \%$ and $8 \%$. The curves also show that as peak temperature increases from $90^{\circ} \mathrm{C}$ to $145^{\circ} \mathrm{C}$, both the elastic modulus and tensile strength continue to drop to approximately $86 \%$ and $83 \%$ of those of unheated reference samples, respectively. It's important to observe that although the PVA fibers did not show any mass loss at these temperatures (see TG/DTG curves in Figure 2) they were exposed to temperatures that are higher than the PVA glass transition temperature $\left(\sim 66^{\circ} \mathrm{C}\right)$, as seen in Figure $3 \mathrm{~b}$. The scanning electron microscopy images of the surface of unheated PVA and of the fiber samples heated to $90^{\circ} \mathrm{C}, 110^{\circ} \mathrm{C}$ and $145^{\circ} \mathrm{C}$ did not show significant sign of damage (see Figure 8). 


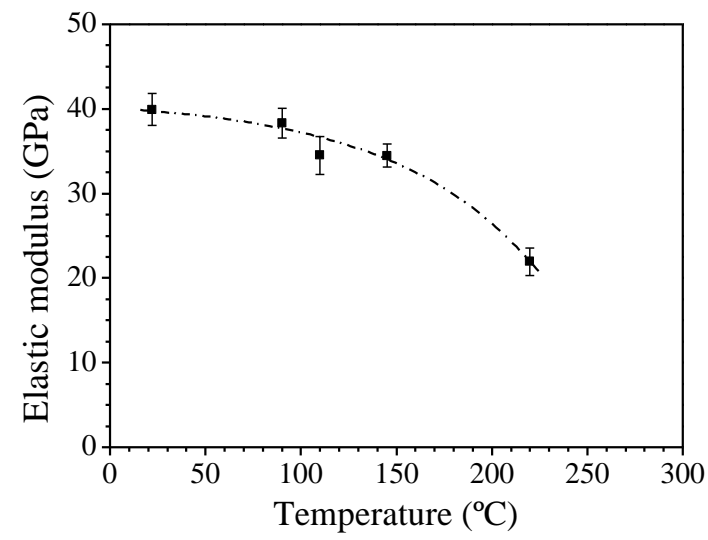

Figure 5: Evolution of elastic modulus of PVA fiber as a function of temperature

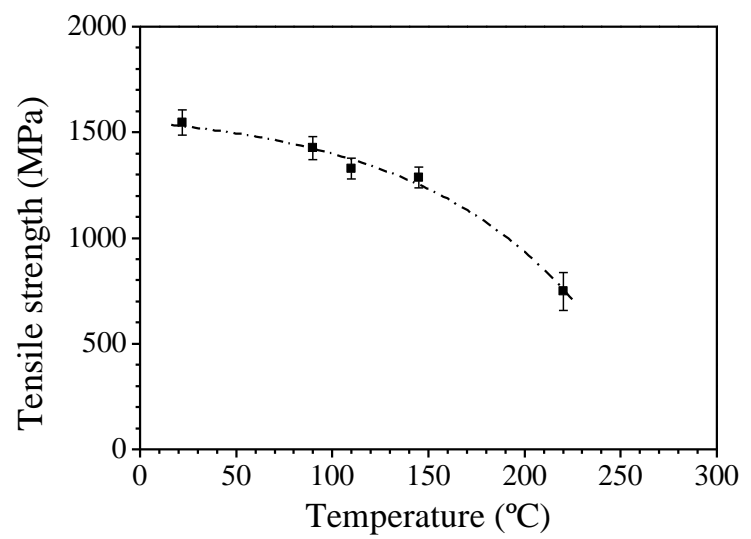

Figure 6: Evolution of strength of PVA fiber as a function of temperature

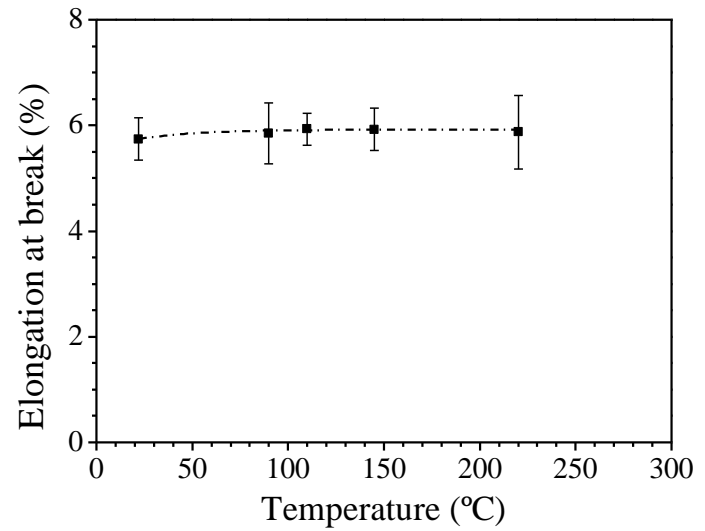

Figure 7: Evolution of elongation at break of PVA fibers as a function of temperature

When the samples were subjected to temperatures in the range of $220-250^{\circ} \mathrm{C}$ the deterioration was quite significant. For example, the residual elastic modulus and strength of the fibers heated up to $220^{\circ} \mathrm{C}$ were approximately $50-55 \%$ of those of unheated reference samples. The fibers subjected to $250^{\circ} \mathrm{C}$ melted (see Figure 8f) and, therefore, tensile tests could not be performed. These results are in accordance with the TG/DTG and DSC test results (see Figure 2 and Figure 3) that indicate that the melting point of PVA fibers begins at approximately $200^{\circ} \mathrm{C}$ and thermal degradation initiates at about $239^{\circ} \mathrm{C}$. The microscopic analysis carried out on the surface of PVA fibers heated to temperatures of $220^{\circ} \mathrm{C}$ and $250^{\circ} \mathrm{C}$ (see Figure $8 \mathrm{a}-\mathrm{f}$ ) show changes on the fiber surface, especially for the fiber submitted to $250^{\circ} \mathrm{C}$.

The results of elongation at break (see Figure 7) and density of PVA fiber were not affected when fibers were heated to temperatures up to $220^{\circ} \mathrm{C}$. 


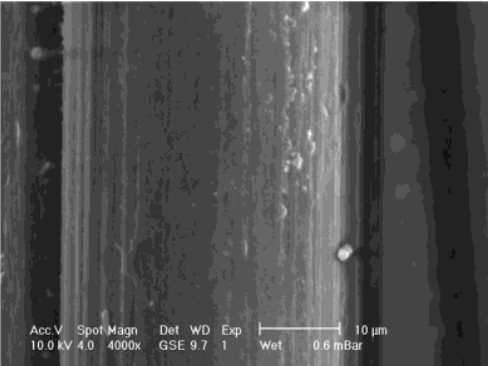

(a)

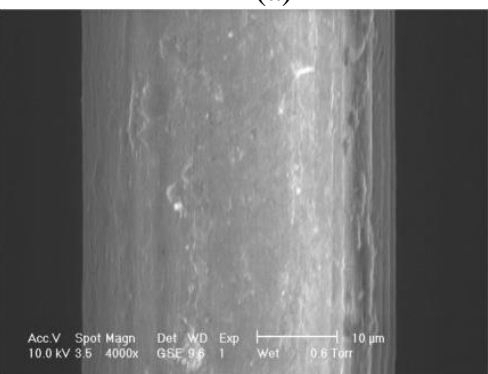

(d)

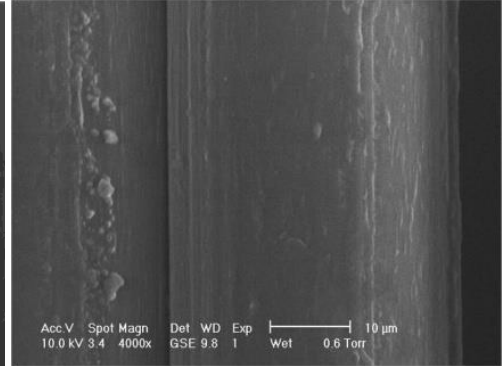

(b)

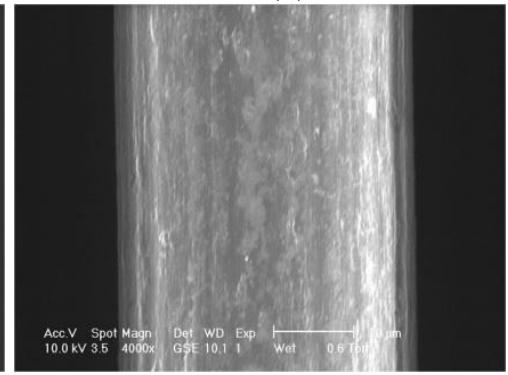

(e)

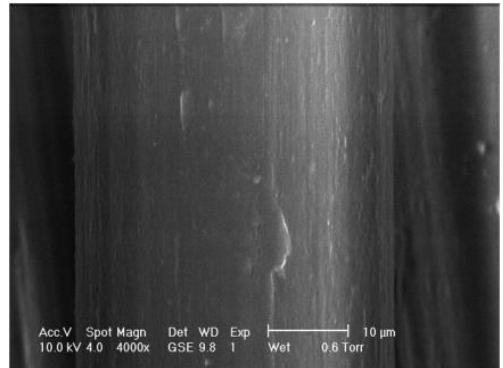

(c)

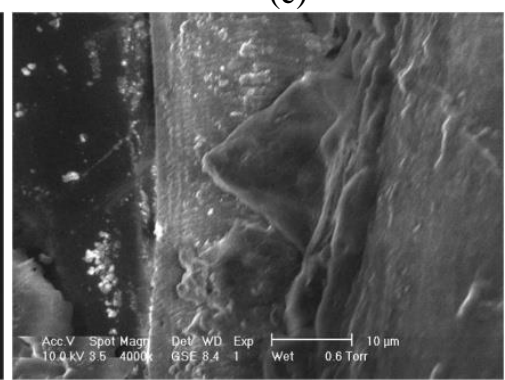

(f)

Figure 8: Scanning electron microscopy images of PVA fiber samples. Unheated (a) and after heating to $90^{\circ} \mathrm{C}(\mathrm{b}), 110^{\circ} \mathrm{C}(\mathrm{c}), 145^{\circ} \mathrm{C}(\mathrm{d}), 220^{\circ} \mathrm{C}(\mathrm{e})$ and $250^{\circ} \mathrm{C}(\mathrm{f})$

Figure 9 shows the influence of temperature on the Weibull modulus. As the Weibull modulus $(\mathrm{m})$ is a measure of the amount of scatter in the sample strength, the high value of the Weibull modulus observed for PVA fiber indicates a relatively high uniformity of this fiber for temperatures up to $145^{\circ} \mathrm{C}$. However, samples heated to $220^{\circ} \mathrm{C}$ showed a sudden drop in Weibull modulus, indicating that significant change occurred in the populations of fracture inducing flaws in this temperature level. The differences in Weibull modulus can be attributed to the nature and distribution of the flaws that may be present in the fibers after heating to a temperature that is very closed to its melting point. The appearance of these defects in the fiber, may affect not only their tensile strength but also the Weibull modulus.

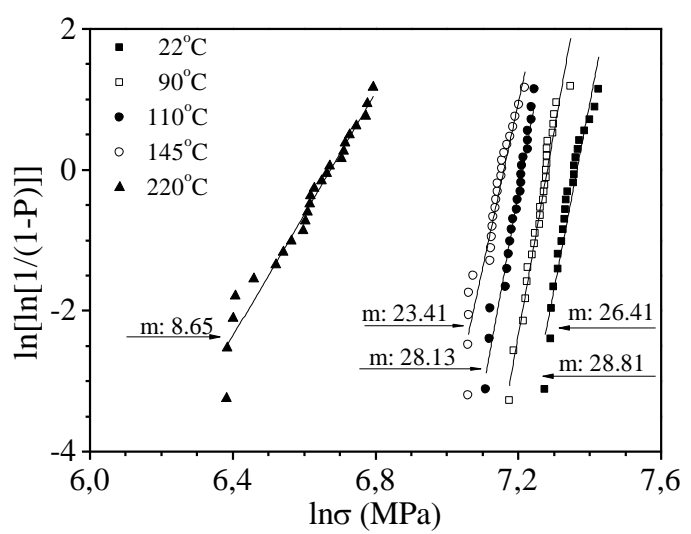

Figure 9: Weibull plots of PVA fiber at different temperatures

\section{CONCLUSIONS}

The experiments developed and conducted in this study delivered results on the PVA fibers behaviour, which are commonly used in manufacturing of strain hardening cementitious composites, after exposure to different temperatures levels. On the basis of the experimental results, the following conclusions can be drawn:

The presented results showed that up to $145^{\circ} \mathrm{C}$ the loss in stiffness and strength of the fibers is in the range of $14-17 \%$. At $220^{\circ} \mathrm{C}$, however, the elastic modulus and strength were reduced to approximately $55 \%$ and $48 \%$ respectively of those of unheated reference samples.

According to thermal analysis, a PVA fiber presents the glass transition temperature at approximately $66^{\circ} \mathrm{C}$ and an onset melting temperature of about $200^{\circ} \mathrm{C}$. In addition, the fiber begins to decompose at temperatures of approximately $239^{\circ} \mathrm{C}$. 
Regarding to Weibull statistic analysis, the Weibull modulus, "m", was calculated to be 26.41 for unheated PVA sample and $28.81,28.13,23.41$ and 8.65 for PVA samples heated up to $90^{\circ} \mathrm{C}, 110^{\circ} \mathrm{C}, 145^{\circ} \mathrm{C}$ and $220^{\circ} \mathrm{C}$, respectively. The results clearly show that the heated PVA sample up to $220^{\circ} \mathrm{C}$ has the lowest Weibull modulus and tensile strength, while there were not significant changes in the Weibull modulus for other heating temperatures.

\section{ACKNOWLEDGEMENTS}

The authors acknowledge the Brazilian National Council of Research and Development (CNPq), the Scientific and Technological Research agency of the Rio de Janeiro state (FAPERJ) and the Quality Improvement Program for Universities of the Ministry of education and Culture (CAPES) for the financial support and Kuraray Co. Ltd - Japan for donating samples of PVA fiber.

\section{REFERENCES}

[1] ZHENG, Z.H., FELDMAN, D., "Synthetic fiber-reinforced concrete”, Progress in Polymer Science, v. 20, n.2, pp. 185-210, Feb. 1995.

[2] SAITO, T., HORIKOSHI, T., HOSHIRO, H., "Progress of PVA fiber reinforced cementitious composites", In: Proceedings of the Fourth International Workshop on High Performance Fiber Reinforced Cementitious Composites (HPFRCC4), pp. 391-398, Ann Arbor, USA, June, 2003.

[3] KALBSKOPF, R., LHONEUX, B., VAN, DER., et al, "Durability of fiber-cement roofing products", In: Proceeding of Inorganic-bonded Wood and Fiber Composites Material, v. 8, pp. 347-353, Sun Valley, USA, 2002.

[4] BENTUR, A., MINDLESS, S., Fiber-Reinforced Cementitious Composites, 2 ed., Taylor \& Francis, London, 2007.

[5] OGAWA, A., HOSHIRO, H., "Durability of Fibers", In: Van Zijl, G. P.A.G., Wittann, F.H. (eds), Durability of Strain-Hardening fibre-reinforced Cement-Based Composites (SHCC), RILEM State of the Art Reports, v. 4, Chapter 6, Springer, 2011.

[6] LI, V.C., WU, C., WANG, S., et al., "Interface tailoring for strain-hardening polyvinyl alcoholengineered cementitious composite (PVA-ECC)", ACI Materials Journal, v. 99, n. 5, pp. 463 - 472, Sep. 2002.

[7] WANG, S., LI, V.C., "Polyvinyl alcohol fiber reinforced engineered cementitious composites: material design and performances", In: Proceedings of the International RILEM Workshop on High Performance Fiber Reinforced Cementitious Composites (HPFRCC) in Structural Applications, pp. 65-73, Honolulu, Hawaii, USA, May, 2005.

[8] WANG, S., LI, V.C., "Tailoring of PVA fiber/matrix interface for engineered cementitious composites (ECC)," In: Symposium in Advanced Flexible Materials and Structures: Engineering with Fiber, pp. 91-92, Loughborough, UK 2003.

[9] YANG, E.H, YANG, Y.Z., LI, V.C. "Use of high volumes of fly ash to improve ECC mechanical properties and material greenness”, ACI Materials Journal, v. 104, n.6, pp. 620-628, 2007.

[10] AMERICAN SOCIETY FOR TESTING AND MATERIALS, Standard test method for tensile properties of single textile fibers, ASTM D3822-07, 10p, 2007.

[11] SILVA, F.A., CHAWLA, N., TOLEDO FILHO, R.D., 'Tensile behavior of high performance natural (sisal) fibers”, Composite Science and Technology, v.68, n. 15-16, pp. 3438-3443, Dec. 2008.

[12] CHAWLA, N., KERR, M., CHAWLA, K.K. "Monotonic and cyclic fatigue behavior of high performance ceramic fibers", Journal of the American Ceramic Society, v. 88, n. 1, pp. 101- 108, Jan. 2005.

[13] SULLIVAN, J.D., LAUZON, P.H., "Experimental probability estimators for Weibull plots", Journal of Materials Science Letters, v. 5, n.12, pp 1245-1247, May 1986.

[14] WEIBULL, W. STOCKHOLM, S., “A statistical distribution function of wide applicability”, Journal of Applied Mechanics, v. 18, pp. 293-297, 1951.

[15] TSUCHIYA, Y, SUMI, K., "Thermal decomposition products of poly(vinyl Alcohol)", Journal Polymer Science Part: A-1: Polymer Chemical, v. 7, n.11, pp. 3151-3158, May 1969.

[16] TUBS, R.K., TING, K.W., 'Thermal properties of polyvinyl alcohol”, In: C.A. Finch (ed.), Polyvinyl Alcohol-Properties and Applications, Chapter 8, London, John Wliley \& Sons, 1973. 
[17] GILMAN, J.W., VANDERHART, D.L., KASHIWAGI, T., "Thermal decomposition chemistry of poly (vinyl alcohol). Characterization and reactions with bismaleimides", In: fire and Polymers II: Materials and test for Hazard Prevention, Proceedings of the American chemical Society, ACS Symposium series 599, Washington DC, pp. 161-185, Aug 1995.

[18] AMERICAN SOCIETY FOR TESTING AND MATERIALS, Standard test method for assignment of the glass transition temperatures by differential scanning calorimetry, ASTM E1356-08, 4p, 2008.

[19] MARK, H.F. Encyclopedia of polymer science and technology, 4th eds, v. 15, New York, John Wiley and Sons, 2014.

[20] FELDMAN, D., BARBALATA, A., Synthetic polymers: technology, properties, applications, 1 ed., London, ed. Chapman and Hall, 1996.

[21] HORIKOSHI, T., OGAWA, A., SAITO, T, et al., "Properties of PVA fiber as reinforcing materials for cementitious composites". In: Proceedings of the International RILEM Workshop on High Performance Fiber Reinforced Cementitious Composites (HPFRCC) in Structural Applications, pp. 145-154, Honolulu, Hawaii, USA, May, 2005.

[22] MOTTA, L. A. C., Caracterização de fibras curtas empregadas na construção civil, In: Boletim técnico da Escola Politécnica da Universidade de São Paulo, Escola Politécnica-Departamento de Engenharia de Construção Civil-USP, São Paulo, 2007. 